\title{
Transforaminal Epidural Blood Patch
}

Lawrence Weil, MD¹, Richard I. Gracer, MD², and Neal Frauwirth, MD

From: ${ }^{1}$ Integrated Pain Management, Concord, CA, and ${ }^{2}$ Gracer Medical Group, San Ramon, CA

Drs Weil and Frauwith ${ }^{1}$ are in private practice affiliated with Integrated Pain Management Concord, CA.

Dr. Gracer $^{2}$ is in private practice affiliated with the Gracer Medical Group, San Ramon, CA. Dr. Frauwirth ${ }^{1}$ is with Integrated Pain Management

Address correspondence: Dr. Lawrence Weil Integrated Pain Management 2485 High School Ave Ste 201 Concord, CA 94520

Disclaimer: No external funding was provided. Conflict of interest: None.

Manuscript received: 02/05/2007 Revisions accepted: 04/20/2007 Accepted for Publication: 05/09/2007

Free full manuscript: www.painphysicianjournal.com
Spinal headache is an occasional, but painful complication of epidural injection procedures due to dural puncture that allows leakage of CSF from the thecal sac, thereby reducing intracranial pressure. In the event of failure of conservative management, (e.g. abdominal binder, fluids, acetaminophen), an epidural blood patch is often used.

This case report describes a patient with spinal headache after a transforaminal selective epidural injection in a post laminectomy patient that was treated with a transforaminal epidural blood patch after the failure of conservative management. The patient underwent left transforaminal epidural injections at L5 and S1 for management of chronic low back pain secondary to post laminectomy syndrome. Three days later, the patient presented with a severe post lumbar puncture headache and failed to respond to conservative management. Interlaminar epidural approach for blood patch was not feasible secondary to prior laminectomy. Transforaminal epidural blood patch was performed utilizing $2 \mathrm{~mL}$ of autologous blood at each of the two sites. The patient recovered well without headache.

In cases, with inability to perform interlaminar blood patch, a transforaminal approach may be considered.

Key words: blood patch, epidural, spinal headache, transforaminal

Pain Physician 2007; 10:579-582

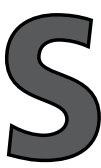
pinal headache is an occasional, painful complication of epidural injection procedures. One study found that there were 10 cases in a total of 453 patients, who had 7,963 spinal injections (1). It is caused by dural puncture that allows leakage of CSF from the thecal sac, thereby reducing intracranial pressure. Initial treatments can include avoiding head elevation, increased fluids, caffeine, acetaminophen, and use of an abdominal binder. If these are not successful, and the patient remains symptomatic the epidural blood patch is the "gold standard" for treatment $(2,3)$. An interlaminar approach for the epidural blood patch is almost always used as this approach is the most commonly used for the original epidural injection, especially in $\mathrm{OB}$ anesthesia, and the most likely to result in spinal headache $(4,5)$.

This paper describes a case of spinal headache after a transforaminal selective epidural injection in a post laminectomy patient that was treated with a blood patch injected via the same route.

A detailed search of existing medical literature indicated that to date there are no previous studies 
discussing the use of the transforaminal approach for an epidural blood patch in the lumbar area. There is a case report of a cervical transforaminal blood patch being used successfully after 2 interlaminar patches had failed (6).

\section{Case Description}

The patient is a 48-year-old male with a history of L5-S1 laminectomy with radicular pain, who had a 2-level selective, transforaminal epidural injection at the left L5 and S1 under fluoroscopic guidance. The L5 and the S-1 roots were both injected as the patient's symptoms referred to both of these levels and a prior procedure at the same locations had resulted in several months reduction in pain. An experienced physician performed the procedure. Contrast was injected to confirm proper needle placement and that there was no vascular flow (Fig.1). Three days later, he presented with a severe headache that worsened when he stood or sat in an upright position and decreased when he was supine. The patient gave a history of having fallen in the bathtub approximately 3 days prior to the original injection, injuring the skin in the caudal area. Past medical history was remarkable for a lumbar laminectomy at the L5-S1 level. The patient had undergone an MRI 3 months prior to the initial transforaminal injection that did not reveal any evidence of a Tarlov cyst or other unexpected pathology. Physical examination revealed normal vital signs and neurologic examination. A well-healed surgical scar was noted posteriorly over L5-S1. In the caudal area at the sacral hiatus, a small ulceration surrounded by very mild erythema was noted. The headache was diagnosed as a spinal headache.

The patient had tried extra fluids, remaining supine, and an abdominal binder with limited success. Due to the severity of the headache, the patient was referred for an epidural blood patch.

The standard interlaminar epidural approach was not appropriate for multiple reasons. First, the patient had a prior laminectomy at the L5-S1 level (Fig. 2). If a blood patch was performed via the interlaminar approach at that level, the likely presence of post operative epidural fibrosis might block the passage of the blood to the presumed leak site at the nerve root sleeve of L5 or S1 (Fig. 3). Also, possible obliteration of the epidural space due to the laminectomy at that level might also lead to a second dural puncture, making the problem worse. Placing the patch at the L4-L5 level, while not likely to cause another dural punc-

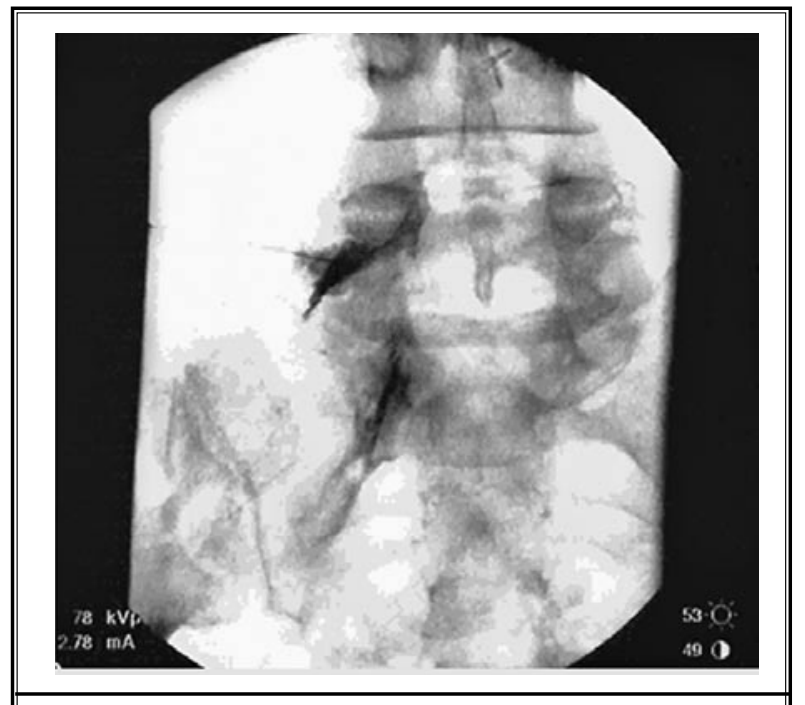

Fig. 1. L5-transforaminal epidural

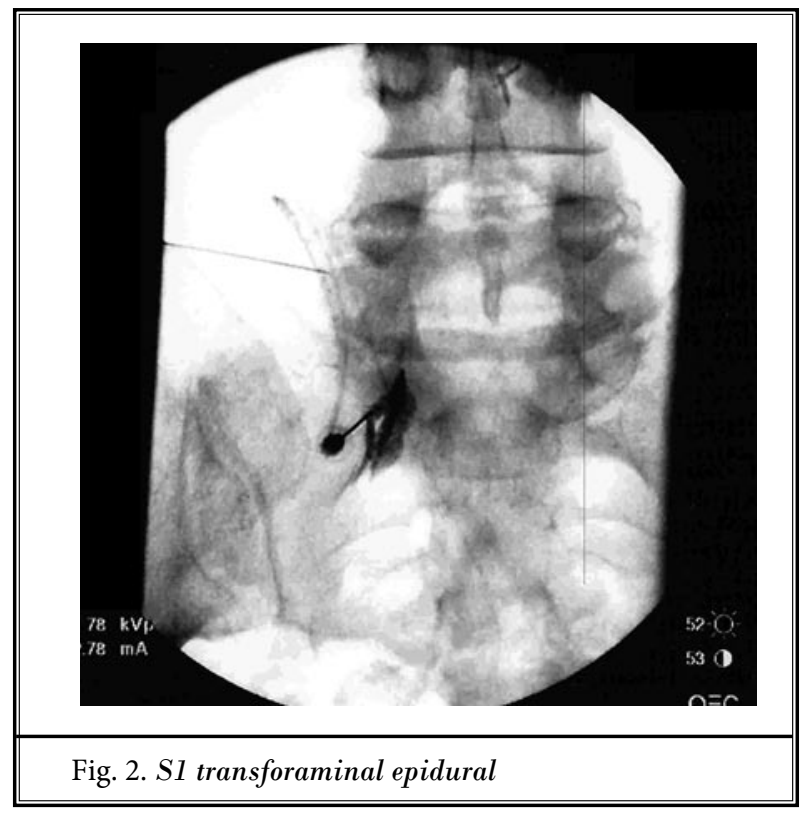

ture, would also be likely to fail due to the preferential cephalad spread of blood in the lumbar epidural space, as well as the postoperative epidural fibrosis. A caudal approach with catheter was also considered, but the sacral dermal ulceration eliminated this pathway. There are anecdotal reports of using a myelogram to detect the site of the leak. In this case we chose to perform the blood patch without doing a myelogram as it is much less invasive with minimal patient risk and avoided needless $x$-ray exposure. We therefore decided to perform a transforaminal epidural blood patch 


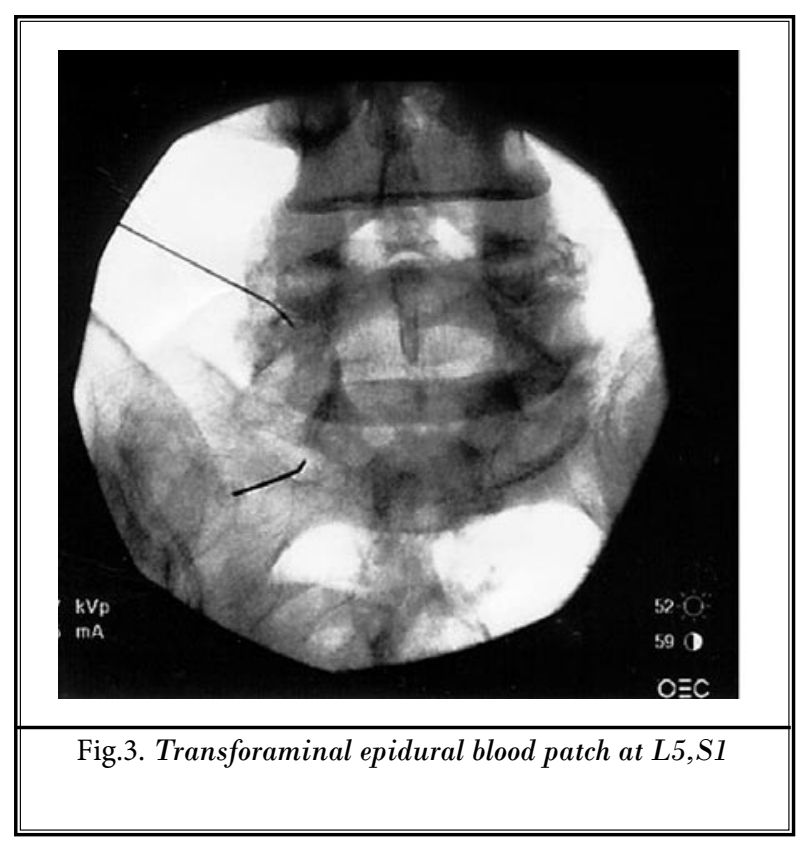

at the L5 and S1 levels on the left side, the site of entry of the initial injections.

The risks and benefits of this procedure, as well as the reasoning behind the above decision were extensively discussed with the patient. The patient indicated that he had "10/10 pain" at the time of presentation and wished to do whatever he could to avoid further headache.

\section{Brief Procedural Summary}

The patient was taken to the fluoroscopy suite after risks, benefits, and options were explained and consent was obtained. He was placed in the prone position. The skin on the patient's forearm was prepped and draped in order to draw blood under sterile conditions at the appropriate time. After prepping, draping, and injection of local anesthesia to the skin over the L5 and S1 foramina, 3.5-inch \#22 gauge needles were inserted to the proper locations under fluoroscopic guidance.

Contrast was not used in this case due to anecdotal reports of contrast inhibiting the clotting of blood. $A P$ and lateral views were used to confirm proper needle placement and aspiration for blood and CSF was negative.

Two $\mathrm{mL}$ of autologous blood was then instilled at each of the 2 sites. This limited volume was chosen due to the small area of the nerve root sleeve in order to effectuate the blood patch, but to avoid local compression and possible nerve root damage.

\section{Patient follow Up}

In the recovery room, approximately 5 minutes after the procedure, the patient was able to sit up and stand up and indicated he was significantly better. His headache was decreased from a 10/10 to $1 / 10$. The patient was then given an additional $500 \mathrm{~mL}$ of normal saline. He had tolerated the procedure well and was discharged. Approximately one week following the procedure, the patient was again followed up by both his regular physician and seen briefly by the injecting doctor as well. He was doing well, without complaints of headache. His back pain had gotten significantly worse after the patch, but this had subsided after several days and was much improved over the pre-epidural pain level. He was headache free.

\section{Discussion}

During the past several decades, the epidural blood patch has been shown to be the gold standard of treatment for dural puncture (5). This procedure consists of a sterile injection of autologous blood at or below the level of the previous dural puncture (due to preferential cephalad spread of the blood in the lumbar epidural space) (7). The mechanism of action for an epidural blood patch is most likely due to stopping CSF loss by formation of a clot over the defect in the meninges, as well as a tamponade effect that raises CSF pressure (8). Following the successful performance of an epidural blood patch, maintenance of the decubitus position for at least one and preferably 2 hours may result in a more complete resolution of symptoms (9). Avoidance of lifting, Valsalva maneuvers, and air travel for 24 to 48 hours after the patch procedure are commonly advised to minimize the risk of patch disruption.

Minor side effects are common following a standard paramedian epidural blood patch. The patient should be warned to expect aching in the back, buttocks, or legs (seen in approximately $25 \%$ of patients) (4). Despite these symptoms, patient satisfaction with the epidural blood patch is generally high. Although controversial, it appears that a previous epidural blood patch does not significantly influence the success of future epidural intervention (10).

In this patient, there appeared to be little choice but to use the transforaminal route. A lumbar surgery had been performed at the best level of entry, L5-S1 in this case. In addition, the original dural puncture was made by a transforaminal entry. Also, it was feared that in a standard approach, scar tissue or fibrotic 
tissue would block the blood patch from the actual puncture site. A caudal approach with catheter was also contemplated; however, the patient had a skin lesion immediately in the area of needle entry for a caudal epidural due to recent trauma. Although the effect of all these factors was not clearly known, it was felt overall the standard blood patch would have less of a chance of being effective.

A volume of $2 \mathrm{~mL}$ of blood was chosen per foramen as it was felt that this would have the best chance of decreasing the headache and having a blood patch effect, yet spare the nerve root from compression issues or subsequent radicular pain from the blood patch. The result in this case was excellent.

\section{Conclusion}

In cases, where spinal headache is caused by transforaminal nerve root sleeve injection, a transforaminal approach for a blood patch should be a consideration.

\section{References}

1. Willburger RE, Knorth H, Haaker R. Side effects and complications of injection therapy for degenerative spinal disorders. Z Orthop Ihre Grenzgeb 2005; 143:170-174.

2. Paech M, Banks S, Gurrin L. An audit of accidental dural puncture during epidural insertion of a Tuohy needle in obstetric patients. Int J Obstet Anesth 2001; 10:162-167.

3. Safa-Tisseront $\mathrm{V}$, Thormann F, Malassine P, Henry M, Riou. B, Coriat P, Seebacher J. Effectiveness of epidural blood patch in the management of post-dural puncture headache. Anesthesiology 2001; 95:334-339.

4. Banks S, Paech M, Gurrin L. An audit of epidural blood patch after acciden- tal dural puncture with a Tuohy needle in obstetric patients. Int J Obstet Anesth 2001; 10:172-176.

5. Harrington BE. Postdural puncture headache and the development of the epidural blood patch. Reg Anesth Pain Med 2004; 29:136-163; discussion 135 .

6. Slipman $\mathrm{CW}, \mathrm{El} \mathrm{Abd} \mathrm{OH,} \mathrm{Bhargava} \mathrm{A,}$ DePalma MJ, Chin KR. Transforamina cervical blood patch for the treatment of post-dural puncture headache. Am J Phys Med Rehabil 2005; 84:76-80.

7. Szeinfeld M, Ihmeidan IH, Moser MM, Machado R, Klose KJ, Serafini AN. Epidural blood patch: Evaluation of the volume and spread of blood injected into the epidural space. Anesthesiology 1986; 64:820-822.

8. Vakharia SB, Thomas PS, Rosenbaum $\mathrm{AE}$, Wasenko JJ, Fellows DG. Magnetic resonance imaging of cerebrospinal fluid leak and tamponade effect of blood patch in postdural puncture headache. Anesth Analg 1997; 84:585-590.

9. Martin R, Jourdain S, Clairoux M, Tetrault JP. Duration of decubitus position after epidural blood patch. Can J Anaesth 1994; 41:23-25.

10. Hebl JR, Horlocker TT, Chantigian RC, Schroeder DR. Epidural anesthesia and analgesia are not impaired after dural puncture with or without epidural blood patch. Anesth Analg 1999; 89:390-394. 